\title{
Hipoteza Sapira-Whorfa - przegląd argumentów zwolenników i przeciwników
}

\section{KEY WORDS}

epistemology, natural and artificial languages, relativism, linguistic universals

\begin{abstract}
Klimczuk Andrzej, Hipoteza Sapira-Whorfa - przegląd argumentów zwolenników i przeciwników [Sapir-Whorf Hypothesis - a Review of Argumentation of Followers and Adversaries]. Kultura - Społeczeństwo - Edukacja nr 1 (3) 2013, Poznań 2013, pp. 165-181, Adam Mickiewicz University Press. ISBN 978-83-232-2631-4. ISSN 2300-0422

Nowadays is growing importance of interdisciplinary research and in the field of cultural diversity, multiculturalism and intercultural cooperation. It is important also to take into account the global processes of changes associated with the dissemination of digital information and communication technologies. One of the theories which are essential in this area of research is the concept by E. Sapir and B.L. Whorf. The purpose of the article is to introduce into a current condition of scientific dispute concerning the views of these authors on the relationship between language and cognition. Paper is based on a critical analysis of the literature. In conclusion, the main findings and recommendations for further research were identified.
\end{abstract}

\section{Wprowadzenie}

Celem niniejszego opracowania jest krytyczny przegląd literatury przedmiotu dotyczącej poglądów Edwarda Sapira i Benjamina Lee Whorfa, a określanych łącznie mianem „hipotezy Sapira-Whorfa”. W tym miejscu uznaje się, iż spór naukowy dotyczący poglądów tych autorów na relacje pomiędzy językiem a poznaniem pozostaje aktualny w kontekście współczesnego wzrostu znaczenia badań interdyscyplinarnych oraz badań z zakresu zróżnicowania kulturowego, wielokulturowości i współpracy międzykulturowej. Jednocześnie obserwujemy globalne przemiany związane z upowszechnianiem cyfrowych technologii informatycznych i telekomunikacyjnych. Koncepcja Sapira i Whorfa wydaje się inspirująca w przypadku badań nad współcześnie podzielonym, sfragmentaryzowanym dyskursem publicznym, w którym coraz więcej przekazów i dyskusji odbywa się nie tylko poprzez 
media masowe, lecz także w zróżnicowanych i często zamkniętych grupach za pośrednictwem takich form komunikacji, jak: poczta elektroniczna, komunikatory internetowe, grupy i fora dyskusyjne, serwisy społecznościowe zgodne $\mathrm{z}$ nurtem Web 2.0, czaty, serwery i systemy wymiany plików, telefonia internetowa, telekonferencje, faks, radio, telewizja, sklepy i aukcje internetowe oraz gry sieciowe. Opracowanie opiera się na krytycznej analizie literatury przedmiotu dotyczącej hipotezy Sapira-Whorfa. Po przybliżeniu jej założeń przeprowadzona została dyskusja nad argumentami jej zwolenników i przeciwników. W podsumowaniu wskazano główne wnioski i rekomendacje co do dalszych kierunków badań.

\section{Hipoteza Sapira-Whorfa}

Myśl przewodnią koncepcji Edwarda Sapira i Benjamina Lee Whorfa stanowi twierdzenie, iż ludzkie myślenie jest zdeterminowane przez język (Słaboń, 2001: 58). Struktury językowe warunkują postrzeganie, klasyfikowanie, sposoby ujmowania rzeczywistości przez człowieka, wpływają na jego stan świadomości i cechy myślenia o rzeczywistości. W konsekwencji w samym języku zawiera się do pewnego stopnia obraz świata. Jak zauważa Andrzej Słaboń, kluczowe idee tej hipotezy powstały na przełomie lat 20. i 30. XX wieku i są zbliżone do wcześniejszych prac Ludwiga Wittgensteina (Słaboń, 2001: 58). Filozof ten, analizując powiązania języka prywatnego i publicznego, doszedł do wniosku, że „granice mego języka oznaczają granice mego poznania" (Wittgenstein, 1997: 64). Alan Barnard i Jonathan Spencer natomiast szukają źródeł poglądów Sapira i Whorfa w pracach niemieckiego językoznawcy porównawczego Wilhelma von Humboldta, który twierdził, że język, w którym odbija się światopogląd („duch”) narodu, wpływa na poznawanie rzeczywistości i dopiero znajomość innego języka pozwala uświadomić sobie ograniczenia narzucane przez język ojczysty (Barnard, Spencer, 2008: 546). Andrzej Słaboń zwraca uwagę, iż podobne do hipotezy Sapira-Whorfa stanowisko w tym samym okresie głosili również Charles Ogden i Ivor Armstrong Richards - autorzy kontekstualnej teorii znaków. Niemniej, jak twierdzi Adam Schaff, nie ma dowodów na to, że Sapir i Whorf swoje poglądy kształtowali, opierając się na teorii Humboldta, stąd też zakładanie, że poglądy te są tożsame, jest błędne i bardzo powierzchowne (Schaff, 1982: 9). Pewne jest natomiast, iż kształtowały się one w ramach etnolingwistycznych badań amerykańskiej szkoły antropologicznej wywodzącej się od Franza Boasa. Niemniej jednak hipoteza Sapira-Whorfa nie jest zbieżna z poglądami tego badacza, gdyż choć podkreślał on, że badania lingwistyczne są potrzebne na gruncie etnografii, to wyraźnie odrzucał teorie przyznające językowi twórczą rolę w stosunku do kultury, uznając odwrotny kierunek tej relacji (Schaff, 1982: 9). 
W nawiązaniu do typologii klasyfikacji znaków według Walerego Pisarka stwierdza się, że hipoteza Sapira-Whorfa mieści się w nurcie teorii określanych łącznie mianem relatywizmu językowego (Pisarek, 2008: 49). Nurt ten poza nimi reprezentowali też członkowie niemieckiego towarzystwa naukowego „Sprache und Gemeinschaft", tacy jak H. Gripper, L. Weisgerber, J. Trier i W. Porzig. Poglądy tych badaczy niekiedy określane są mianem neohumboldtyzmu. Za główną cechę łączącą je $\mathrm{z}$ twierdzeniami Humboldta uznaje się przekonanie o wzajemnych związkach między językiem a poglądem na świat i charakterem narodu, które wynikają z roli języka w poznawaniu i przedstawianiu rzeczywistości. W skrócie relatywizm językowy sprowadza się do modelu, w którym język oddziałuje na myślenie, filtrując postrzeganą rzeczywistość, jak również filtrując myślenie, oddziałuje na rzeczywistość przedstawianą.

Według Tomasza Nowaka w hipotezie Sapira-Whorfa relatywizm przyjmuje trzy znaczenia (Nowak, 2011: 311-312): (1) deskryptywny, który postuluje konieczność akceptacji różnych kultur, a co za tym idzie, różnych sposobów percepcji, kategoryzacji i interpretacji świata, (2) normatywny, który sugeruje brak uniwersalnych standardów: logicznych, etycznych i estetycznych, (3) epistemologiczny, zakładający brak jedności ludzkiej psychiki i krytykę ogólnych teorii kultury. Relatywistyczna teoria języka przyjmuje postać słabszą (poglądy E. Sapira) i mocniejszą (poglądy B.L. Whorfa), które sytuują się pomiędzy relatywizmem deskryptywnym i epistemologicznym. Podobnie twierdzą A. Barnard, J. Spencer i A. Schaff (Barnard, Spencer, 2008: 545; Schaff, 1982: 20). Nieco odmienną typologię przedstawia Anna Jedynak, która wskazuje na trzy stopnie rozumienia relatywizmu językowego reprezentowanego przez Sapira i Whorfa (Jedynak, 2007: 85-86). W wersji najsłabszej języki różnych społeczności etnicznych różnią się niekiedy dość znacznie brzmieniem słów i ich znaczeniem, a co za tym idzie, różnią się światopoglądy posługujących się nimi społeczności. Jest tak dlatego, że język kształtuje sposób widzenia i interpretowania świata. W wersji mocniejszej światopoglądy te są nie tylko różne, ale też nie da się ich ze sobą pogodzić - przyjęcie jednego wyklucza uznanie innych. Trzeci stopień relatywizmu językowego to stanowisko stanowiące pomost między wersją słabszą i mocniejszą, które głosi, że wśród języków kształtujących światopoglądy nie ma lepszych ani gorszych wszystkie są równie dobre.

Niezbędne jest przybliżenie i odróżnienie głównych poglądów Sapira i Whorfa. W koncepcji tego pierwszego kultura stanowi system symboliczny (Nowak, 2011: 312). Symbole łączą w sobie trzy aspekty: interpretację, referencję i substytucję. Każdy symbol ma znaczenie dla kogoś, a nie sam w sobie, oraz skupia uwagę na sobie i kieruje ją na coś innego. Jak twierdzi Sapir: „Język jest w ogólnym odczuciu doskonałym systemem symbolicznym, o idealnie jednorodnym materiale, jako narzędzie wszelkich odniesień i znaczeń dostępnych danej kulturze 
zarówno w formie zaktualizowanej komunikacji, jak i w formie takich idealnych substytutów komunikacji, jak myślenie" (Sapir, 1978: 37). Każda treść kulturowa daje się zawsze wyrazić w jakimś języku, pozwala na wyjście poza jednostkowe doświadczenie. Język cechuje się jednorodnością, złożonością i uniwersalnością. Gwarantuje percepcję, kategoryzację, symbolizację, komunikację, transcendencję i substytucję rzeczywistości. Ponadto przekazuje znaczenia, czyli wyraża wszystkie możliwe treści kulturowe oraz zrównuje rzeczywistość zewnętrzną i wewnętrzną. Dzięki językowi świat jednej osoby staje się światem wielu. O ile jednostki gromadzą indywidualne doświadczenia, to zbiorowości za pośrednictwem języka gromadzą doświadczenia społeczne. Język kategoryzuje doświadczenia i tworzy ponadindywidualny świat, umożliwiający powszechne porozumienie. Przenika bezpośrednie doświadczenie tak, iż niekiedy trudno odróżnić rzeczywistość przyrodniczą i społeczną od odnoszących się do niej symboli językowych. Język oddziałuje na myślenie, a w konsekwencji na zachowania ludzi. Światy opisywane przez poszczególne społeczeństwa są zatem odrębne i zróżnicowane. Według Sapira

Ludzie nie żyją wyłącznie w świecie obiektywnym ani też wyłącznie w świecie działań społecznych w zwykłym rozumieniu, lecz pozostają w dużej mierze na łasce języka, który stał się środkiem ekspresji w ich społeczeństwie. Iluzją jest wyobrażenie, że przystosowujemy się do rzeczywistości w zasadzie bez użycia języka, który jest tylko niezbyt istotnym narzędziem rozwiązywania specyficznych problemów komunikacji czy refleksji. Prawda wygląda tak, że 'realny świat' jest w znacznej mierze zbudowany nieświadomie na zwyczajach językowych danej grupy. Żadne dwa języki nie są nigdy dostatecznie podobne, by można je było traktować jako reprezentujące tę samą rzeczywistość społeczną. Światy w których żyją różne społeczeństwa, są odrębnymi światami, nie zaś tym samym światem, tylko opatrzonym odmiennymi etykietkami. (Sapir, 1978: 88)

Język zawiera nieuświadomione sądy o świecie i stereotypy, które eksponują lub ukrywają poszczególne cechy rzeczywistości. Ludzie zawsze żyją w świecie zapośredniczonym językowo.

Poglądy Benjamina Lee Whorfa odróżnia się z uwagi na fakt, iż przejmuje on od Sapira zasadę relatywizmu językowego z wszystkimi konsekwencjami, ale bez właściwego mu umiarkowania, oraz iż neguje możliwość poznania obiektywnej rzeczywistości (Schaff, 1982: 20). Autor ten prowadził badania porównawcze standardowych języków europejskich (SAE) i języka Indian Hopi (JIH). Porównywał pojęcia czasu, przestrzeni i materii, poszukując, na ile są zależne od struktury różnych języków i czy przejawiają się w ludzkim doświadczeniu w jednakowej formie (Whorf, 1982: 181). Poszukiwał wspólnych cech norm kulturowych i zachowań oraz wzorów językowych. Obserwacje Whorfa można sprowadzić do kilku przykładów (Nowak, 2011: 313). SAE ujmują materię jako zbiór rzeczy, JIH zaś jako zbiór zdarzeń, w tym obiektywnych, zmysłowych i subiektywnych, psychicznych. 
SAE obejmują rzeczowniki jednostkowe i zbiorowe, natomiast JIH tylko indywidualne, przyjmujące formy liczby pojedynczej lub mnogiej. SAE posługują się rzeczownikami typu lato, zima, zmierzch, poranek, a JIH przysłówkami jak podczas, gdy wydarza się faza południowa. SAE zawierają kategorię czasu teraźniejszego, przeszłego i przyszłego, zaś JIH ujmują łącznie czas i przestrzeń tak, że ten sam czas w różnych miejscach interpretuje się jako inny. SAE wykorzystują metafory przestrzenne, JIH zaś tensory wyrażające łącznie intensywność, tendencję, czas trwania i następstwo (Whorf, 1982: 197-198).

Język w opinii Whorfa jest interpretantem kultury. Leksyka i gramatyka to siatka interpretacyjna, która nakłada się na kalejdoskopowy strumień wrażeń, dzięki czemu powstaje językowy obraz świata. Badacz opisuje te cechy następująco:

\begin{abstract}
Proces formułowania myśli nie jest niezależny i racjonalny w tradycyjnym sensie, lecz stanowi fragment określonej gramatyki i w zależności od niej wykazuje mniejsze lub większe zróżnicowania. Dokonujemy segmentacji natury tropami wyznaczonymi przez nasze języki ojczyste. Wyodrębniamy pewne kategorie i typy w świecie zjawisk nie dlatego, że każdemu obserwatorowi rzucają się one w oczy, wręcz przeciwnie - rzeczywistość jawi się nam jako kalejdoskopowy strumień wrażeń, strukturę natomiast nadaje jej nasz umysł - to jest przede wszystkim tkwiące w naszych umysłach systemy językowe. Dzielimy świat na części, porządkujemy go za pomocą pojęć, przypisujemy mu sens w określony sposób, ponieważ jesteśmy sygnatariuszami umowy, by czynić to tak właśnie, a nie inaczej; umowy, która obowiązuje w naszej społeczności językowej i którą skodyfikowano we wzorcach naszego języka. Umowę tę zawarliśmy implicite i nigdy nie została ona spisana, ale jej warunki obowiązują bezwzględnie - nie jesteśmy w stanie mówić bez zaakceptowania ustanowionych przez nią klasyfikacji danych i ich uporządkowania. (Whorf, 1982: 284-285)
\end{abstract}

Pojęcia języka filtrują zatem świat, a ich regularne wykorzystywanie tworzy wzorce zachowań językowych, charakterystyczne dla danej kultury, a zarazem odrębne światy myślowe. Każdy język kształtuje subiektywną perspektywę i kodyfikuje odmienne katalogi rzeczywistości. Ponadto Whorf, omawiając zagadnienie wzajemnej przekładalności systemów językowych, stwierdza, że „nikt nie potrafi opisać rzeczywistości całkowicie bezstronnie; wszystkich nas krępują pewne prawidła interpretacji nawet wówczas, gdy sądzimy, że jesteśmy wolni. (...) Dochodzimy tu do nowej zasady relatywizmu: postrzegający nie tworzą sobie tego samego obrazu świata na podstawie tych samych faktów fizycznych, jeśli ich zaplecza językowe nie są podobne lub przynajmniej porównywalne" (Whorf, 1982: 285). Przyjęcie tego założenia podważa możliwość komunikacji międzyjęzykowej, wzbudza też pytania o możliwość przekładu i interpretacji znaczeń funkcjonujących w innych kulturach (Wstęp do kulturoznawstwa, 2007: 71), a jednocześnie prowadzi do twierdzenia, że nie zachodzi wyższość jednych języków nad innymi, gdyż wszystkie posiadają swoje wady i zalety (Whorf, 1982: 132-133). 


\section{Argumenty za hipoteza Sapira-Whorfa}

Jak zauważa Andrzej Słaboń, kontrowersje wokół hipotezy Sapira-Whorfa przede wszystkim stymulowały rozwój nauk o języku (Słaboń, 2001: 58). Autor ten dodaje, że współcześnie raczej nie kwestionuje się związku języka z myśleniem, lecz mocną wersję hipotezy, w której język uznaje się za jedyny wyznacznik myślenia. Bardziej wyraziście podobny pogląd wyrażają Barnard i Spencer, twierdząc, że znaczenie hipotezy Sapira-Whorfa „lokuje się mniej w jej możliwej prawdziwości, a bardziej w trwałej zdolności generowania myśli i dyskusji na temat problemu, który jest centralny dla całego projektu antropologicznego" (Barnard, Spencer, 2008: 546). Tym samym sugerują, iż całkowite odrzucenie hipotezy Sapira-Whorfa oznaczałoby przekreślenie zasadności badań nad zróżnicowaniem i rozwojem gatunku ludzkiego prowadzonych na gruncie tak antropologii, jak i innych nauk.

Hipoteza Sapira-Whorfa jest według Tomasza Nowaka prawdziwa przy przyjęciu założenia, że głosi relatywizm kulturowy, a nie językowy (Nowak, 2011: 315). Istotne jest zatem spojrzenie na badane wartości, normy i systemy społeczne z perspektywy kultury danego społeczeństwa, a nie z punktu widzenia kultury badacza. Niezbędne jest zatem odrzucenie racjonalistycznego podejścia kultur cywilizacji zachodniej, które okazuje się etnocentryczne, oraz podejmowanie badań etnograficznych i interpretatywnych ${ }^{1}$. Nowak podaje również, iż argumenty wspierające tezę wynikają z badań eksperymentalnych i badań nad gramatyką (Nowak, 2011: 315-316; Gut, 2009: 31-37). W pierwszym przypadku zaobserwowano różnice między zachowaniami dzieci, które posługują się językami holenderskim i indiańskim tzeltal. Obie grupy otrzymały polecenia, aby obserwować stół X z zabawkami A i B, a następnie odwrócić się i ułożyć zabawki A i B na stole Y, zachowując kolejność zabawek A i B na stole X. Podczas wykonywania zadania dzieci holenderskie kierowały się prawą i lewą ręką, zaś indiańskie kierunkami świata: wschodem i zachodem. Tym samym odmienne są ramy odniesienia dla lokalizacji przedmiotów - w języku holenderskim względne i niezależne od obserwatora, zaś w języku tzeltal absolutne i niezależne od obserwatora. Argumenty gramatyczne dotyczą zaś porównania języka angielskiego i koreańskiego. W pierwszym rzeczownik jest obligatoryjny, w drugim fakultatywny. Derywacja rzeczowników w języku angielskim jest bardziej produktywna niż czasowników, zaś w koreańskim zachodzi odwrotna zależność. W konsekwencji dzieci posługujące się językiem angielskim lepiej nazywają i kategoryzują przedmioty, a koreańskie lepiej nazywają i kategoryzują czynności.

Zdaniem Schaffa poglądy Sapira i Whorfa znajdują zwolenników głównie wśród antropologów i etnolingwistów (Schaff, 1982: 6), niemniej stwierdzają oni,

1 Zob. w: Stownik socjologii i nauk społecznych, hasła Relatywizm kulturowy, s. 277, i Interpretacja, socjologia interpretatywna, s. 131-133. 
że brakuje wystarczających podstaw do ich weryfikacji i falsyfikacji, stąd też noszą miano hipotezy. Podkreśla się przy tym potrzebę dalszych badań nad założeniami i implikacjami twierdzeń relatywizmu językowego. W opinii Schaffa „hipoteza Sapira-Whorfa, bez względu na zarzuty, jakie można by pod jej adresem wysunąć, powstawała bowiem jako uogólnienie - może pochopne i jednostronne, ale jednak uogólnienie - materiału empirycznego. Dlatego właśnie, ktokolwiek chce się dziś zająć rzetelnie i naukowo problemem czynnej roli języka w procesie poznania, musi do tej hipotezy nawiązać (co nie jest bynajmniej równoznaczne $z$ afirmowaniem jej w całej rozciągłości)" (Schaff, 1964: 125). Tym samym zakłada się, że rzetelna analiza hipotezy Sapira-Whorfa oraz próby jej obrony lub krytyki pozwalają na stymulowanie dalszych projektów badawczych, tak, aby uwzględniały dotychczasowe niepowodzenia i błędy. Przykładowo Mirosława Marody podaje za Joshuą Aaronem Fishmanem typologię poziomów analiz podejmowanych w celu weryfikacji hipotezy Sapira-Whorfa (Marody, 1987: 38-44). Obejmuje ona cztery rodzaje cech językowych, czyli „zmiennych wyjaśniających” oraz „zmiennych” wyjaśnianych wpływami języka. Pierwszy poziom weryfikacji dotyczy leksykalnego zróżnicowania języków - czy istnienie danego terminu językowego ułatwia członkom danej społeczności uświadamianie i wyrażenie stanu rzeczy objętego tym terminem. Drugi poziom to związek między różnicami w leksyce a odmiennymi zachowaniami pozawerbalnymi członków różnych społeczności językowych. Trzeci to gramatyczna struktura języka zestawiana z ogólnymi światopoglądami poszczególnych kultur. Czwarty dotyczy związku między gramatyką języka a zachowaniami niewerbalnymi. Uwagi te pozwalają sądzić, iż weryfikacja hipotezy Sapira-Whorfa stanowi wymagające zadanie badawcze. Ponadto Barnard i Spencer wskazują, że weryfikacja hipotezy wymagałaby określenia jakiejś formy nielingwistycznych świadectw procesów umysłowych oraz sposobu opisu cech różnych języków, które są odpowiedzialne za odmienne sposoby myślenia z wyłączeniem mowy własnej badaczy (Barnard, Spencer, 2008: 546). Autorzy ci podają również przykład badań Johna Lucy’ego, który wychodząc od takich pytań, stworzył opisowy „metajęzyk”, niezależny od dwóch porównanych języków: angielskiego i Yucatec Maya. Psycholog ten przeprowadził testy lingwistyczne i nielingwistyczne wśród Indian Yucatec i amerykańskich studentów, które pozwoliły na potwierdzenie różnic w językowym postrzeganiu świata przy badaniu własności takich jak kształt i materia. Głównie dotyczyły one zadań obejmujących systematyzację i porównywanie obiektów.

Według Michaela Herzfelda przyjęcie słabszej wersji hipotezy Sapira-Whorfa umożliwia wspólne tworzenie przez przedstawicieli różnych kultur zbieżnych $\mathrm{w}$ wielu punktach interpretacji zjawisk oraz poszerzanie perspektywy poznawczej (Herzfeld, 2004: 259, 303). Może też ułatwiać antropologom aktywne zaangażowanie się w problematykę relacji ludzi i środowiska przyrodniczego oraz pomagać 
w zrozumieniu różnic kulturowych dotyczących opinii i postaw wobec ochrony środowiska. Inne potencjalne kierunki badań oparte na hipotezie Sapira-Whorfa sugerują autorzy oksfordzkiego Słownika socjologii i nauk społecznych. Hipoteza ta może być użyteczna nie tylko dla uznania, iż poszczególne kultury różnią się szczegółowością opisów i wyjaśnień istotnych dla nich spraw, jak na przykład wielość nazw ryżu czy barw śniegu, lecz może też służyć do badań empirycznych przejawów „nowomowy” totalitarnej władzy.

\section{Argumenty przeciwko hipotezie Sapira-Whorfa}

Jak wskazuje Adam Schaff, badacze tacy jak M. Black, Włodzimierz Zwiegincew, Charles Landesman, Georg Brutian, Lewis S. Feuer, J.B. Carroll i Eric Lenneberg wskazywali na szereg zarzutów wobec hipotezy Sapira-Whorfa (Schaff, 1964: 127). Zakładali oni m.in., że

jej kategorie wyjściowe są wieloznaczne i źle definiowane; jej sformułowania są mętne; założenie, że język porządkuje i organizuje 'surowe' poznanie, będące 'kalejdoskopowym strumieniem wrażeń’ - jest metafizyczne; równie metafizyczne jest twierdzenie, że język (pojmowany autonomicznie, a nie jako odbicie rzeczywistości) zawiera w sobie pogląd na świat; teza 'relatywizmu językowego' prowadzi w swej skrajnej postaci do absurdalnego twierdzenia o nieprzetłumaczalności różnych języków. (Schaff, 1964: 127)

Według samego Schaffa skrajna wersja relatywizmu językowego uzależnia całą strukturę poznania od języka co jest poglądem błędnym z przynajmniej czterech powodów (Schaff, 1964: 236-239). Po pierwsze, nawet potoczne obserwacje pozwalają twierdzić, że języki są wzajemnie przetłumaczalne i możliwa jest koordynacja działań ludzi mówiących różnymi językami. Niemniej przekład może wymagać dogłębnej znajomości kultury danego społeczeństwa, gubić obrazy i emocje języka tłumaczonego. Po drugie, gdyby na bazie odmiennych systemów językowych powstawały odmienne obrazy świata, to posługujący się nimi ludzie zachowywaliby się w tych samych warunkach zupełnie inaczej. Po trzecie, wszystkie języki mają pewne wspólne cechy, umożliwiające ich tłumaczenie i porozumiewanie się, co wiąże się z wspólnymi losami biologicznymi w warunkach rzeczywistości ziemskiej. Są nimi tak zwane powszechniki kulturowe, uniwersalia językowe. Po czwarte, języki podlegają ciągłym przemianom z uwagi na zmiany społeczne, kontakty z obcymi kulturami i postęp cywilizacyjny, co w pewnym stopniu prowadzi do zacierania się ich aparatury pojęciowej, choć nie oddziałuje równie wyraźnie na ich fonetykę, gramatykę i zabarwienie obrazowo-emocjonalne.

Ponadto amerykańska szkoła antropologiczna, na gruncie której powstała hipoteza Sapira-Whorfa, nie stanowi jedynej perspektywy badań nad kulturą i językiem. Jak podaje Marian Golka, istotne powinno być jeszcze uwzględnianie 
dorobku przynajmniej takich nurtów teoretycznych jak: ewolucjonizm, neoewolucjonizm, marksizm, szkoła frankfurcka, szkoła durkheimowska, dyfuzjonizm, funkcjonalizm, myślenie systemowe, strukturalizm, psychokulturalizm, antropologia kognitywna, studia kulturowe i postmodernizm (Golka, 2008: 22-26). Badania z zakresu procesów komunikacji według Denisa McQuaila powinny zaś dotyczyć nie tylko analizy kulturalistycznej, która odwołuje się do lingwistyki, ale też do dorobku nauki o komunikowaniu, strukturalizmu i analizy behawioralnej (McQuail, 2007: 35-40). Według Pisarka relatywizm językowy Sapira i Whorfa jest tylko jedną z propozycji klasyfikacji znaków obok koncepcji m.in. Ferdinanda de Saussure'a, Helmuta Gippera i Rolanda Barthesa (Pisarek, 2008: 45-54). Ten pierwszy uznawał, że znak to całość połączenia danego pojęcia (elementu znaczonego, który ludzie mają na myśli, gdy wypowiadają dany znak, słowo) i obrazu akustycznego (elementu znaczącego, który jest surowym ciągiem głosek lub znaków graficznych). Gipper przeciwnie, w sposób zbliżony do relatywizmu językowego uznawał, że znak to wyraz stanowiący jedność dźwięku i treści, która odnosi się do świata zewnętrznego, rozumianego nie jako obiektywna rzeczywistość, lecz jako wszystko, co może zostać uchwycone językowo. Barthes natomiast wskazywał, że możliwa jest też analiza mitów jako znaków drugiego stopnia, powstałych w wyniku połączenia znaku (już składającego się z elementów znaczącego i znaczonego) z dodatkową treścią znaczoną. Przykład stanowią tu na przykład nazwy własne miejscowości, które są związane z mitami o bohaterskich wydarzeniach. Ponadto Piotr P. Chruszczewski wyróżnia cztery paradygmaty językoznawstwa antropologicznego (Chruszczewski, 2011: 91-263). Są to: dokumentacyjny (m.in. pozyskiwanie danych, leksyka jako wskaźnik zmian społeczno-kulturowych), kulturowo-lingwistyczny (m.in. kontakt kulturowy, zmiana językowa, śmierć języka), transformacyjny (m.in. etnografia mówienia, językowe relacje siły i przewagi) oraz komunikacyjno-dyskursywny (m.in. koncepcja kontekstu, zanurzenia tekstów, formy komunikacji). Według tej typologii hipoteza Sapira-Whorfa przynależy tylko do pierwszego paradygmatu i odnosi się do pracy terenowej przy zbieraniu danych oraz do opisu i klasyfikacji języków rdzennych mieszkańców poszczególnych kontynentów.

Innym argumentem wysuwanym przeciwko hipotezie Sapira-Whorfa jest twierdzenie, iż samo określenie 'hipoteza' jest tu stosowane nieprecyzyjnie na określenie zbliżonych, ale nie wspólnych poglądów tych autorów. Adam Schaff zauważa, że hipoteza ta nie jest czymś jednolitym, gdyż każdy z jej autorów reprezentuje w ważnych zagadnieniach poglądy odmienne (Schaff, 1982: 20). Bardziej wyraziście wypowiada się Wojciech J. Burszta: „Hipoteza Sapira-Whorfa jako taka nie została nigdy sformułowana; jest ona jedynie wypadkową poglądów przypisanych tym badaczom przez grono kontynuatorów i uczniów. Z metodologicznego punktu widzenia nie jest to także hipoteza w sensie naukowym" (Burszta, 1998: 71). Podobnie 
Barnard i Spencer sugerują, że właściwe autorstwo omawianej hipotezie powinno się przypisywać Whorfowi, który wprowadził to wyrażenie i przekonywał, że w jego odczuciu Sapir był pierwszym jej autorem (Barnard, Spencer, 2008: 545). Autorzy ci zauważają też, że hipoteza Sapira-Whorfa nie jest wewnętrznie spójna, a część jej argumentów jest zbliżonych do antyrelatywistycznych argumentów Luciena Lévy-Bruhla (Barnard, Spencer, 2008: 545-546). Ich koncepcje są zbieżne co do rozpoznania specyficznych złożoności gramatyk tak zwanych ludów pierwotnych, ale interpretacje są skrajnie odmienne. O ile dla Levy-Bruhla konkretność wyrażeń ludów prymitywnych miała odzwierciedlać ich niezdolność lub niechęć do konstruowania pojęć abstrakcyjnych, dla Whorfa oznaczała zdolność myślenia bardziej precyzyjnego niż w językach skłonnych do abstrakcji. Podczas gdy Levy-Bruhl uznawał, że język jest odbiciem myśli i to myśl pierwotna prowadziła do powstania kategorii gramatycznych, Whorf relacje tą wyjaśniał dokładnie odwrotnie.

Nawet jeśli zachodzi zgoda, iż tak, jak sugeruje hipoteza Sapira-Whorfa, zachodzi związek pomiędzy językiem a myśleniem, to w literaturze przedmiotu nie występuje zgoda co do kierunku relacji przyczynowej (Wstęp do kulturoznawstwa, 2007: 72). Nie ma zgody co do tego, czy jest to jednokierunkowe oddziaływanie języka na myślenie, czy też oddziaływanie zwrotne. Jak wskazuje Jan Woleński, poza hipotezą Sapira-Whorfa istnieją jeszcze przynajmniej trzy stanowiska co do stosunku poznania i języka: Jeana Piageta, iż rozwój poznania poprzedza rozwój języka; Noama Chomsky’ego, iż poznanie i język są wzajemnie niezależne; oraz Lwa Wygotskiego, iż poznanie i język powstały niezależnie, ale stały się współzależne (Woleński, 2005: 456-457). Ponadto zauważa się, że istnieje spór między zwolennikami języków naturalnych i sztucznych (Woleński, 2005: 456-457; Stępień, 1995: 33, 61, 168). Hipoteza Sapira-Whorfa odnosi się tylko do języków naturalnych, inaczej: zastanych, etnicznych, które według zwolenników języków sztucznych są niespójne, służą głównie komunikacji i są oparte na umowie domyślnej, a co za tym idzie, wymagają doprecyzowania, transponowania ich wyrażeń na wyrażenia języka skonstruowanego, formalnego, spójnego, opartego na umowie jawnej i umożliwiające wyrażanie twierdzeń naukowych. Zdaniem Marka Ziółkowskiego przyjmowanie radykalnej wersji hipotezy Sapira-Whorfa i zbliżonych poglądów innych badaczy prowadziło do postawienia tezy, iż poznanie rzeczywistości w istocie w ogóle nie wykracza poza język (Ziółkowski, 1998: 374). Teza ta wiąże się z antypozytywistycznymi wizjami nauki, które głoszą, że nie odbija ona świata, lecz go konstruuje (m.in. Hilary Putnam, Richard Rorty). Zbliżony argument podają autorzy oksfordzkiego Słownika socjologii i nauk społecznych, twierdząc, że słowa często powstają, by odzwierciedlać rzeczywistość, a nie - by ją konstruować. Jako przykład podają słowo „mikrofala”, które było potrzebne do opisu, a nie do wymyślenia kuchenki mikrofalowej².

${ }^{2}$ Zob. w: Stownik socjologii i nauk spotecznych hasło: Hipoteza Sapira-Whorfa, s. 116. 
Argumenty za hipotezą Sapira-Whorfa podważa się również na gruncie dyskusji co do tego, czy można odróżnić myślenie od języka (Wstęp do kulturoznawstwa, 2007: 72; Kłoskowska, 2007: 304-305). Według części strukturalistów (L. Althusser, R. Barthes, N. Chomsky, M. Foucault, J. Lacan, C. Levi-Strauss) nie da się oddzielić myślenia od języka, który stanowi lokalne, charakterystyczne dla danej kultury przejawy procesu oddziaływań między umysłem a środowiskiem. Ich zdaniem formy myślowe są utajone, nieświadome i niedostępne bezpośredniemu badaniu. Język natomiast stanowi lokalnie uwarunkowaną reprezentację oddziaływania na otoczenie ukrytych procesów myślowych. Zakłada się tu, że można badać otoczenie, a nie działanie umysłu, które powinno być obszarem badań nauk przyrodniczych bądź biochemii. W rezultacie postuluje się ograniczenie badań nad otoczeniem do socjolingwistyki - związków między użyciem języka a stosunkami społecznymi oraz etnografii mowy - analizy społecznego kontekstu aktów mowy.

Za Tomaszem Nowakiem dalsze argumenty przeciwko koncepcji determinizmu językowego można podzielić na logiczne, obserwacyjne oraz eksperymentalne - międzyjęzykowe i wewnątrzjęzykowe (Nowak, 2011: 316). Według logiki hipoteza Sapira-Whorfa jest niemożliwa, gdyż jeśli język determinuje myślenie, to nie-Hopi nie może zrozumieć, jak myśli Hopi. Wątek ten rozwija Anna Jedynak. Twierdzi ona, że można przyjąć jedynie pierwszą część słabszej wersji hipotezy, która zakłada, że istnieją różnice między językami i światopoglądami (Jedynak, 2007: 86-87). Nie można jednak przyjąć niewystarczająco udokumentowanego twierdzenia, iż różnice te kształtuje język. Wersja mocniejsza zaś stawia pod znakiem zapytania możliwość porównywania odmiennych poglądów (Jedynak, 2007: 87-88). Jak twierdzi Jedynak:

czym innym jest niemożność uzgodnienia poglądów z powodu braku wspólnych pojęć, a czym innym poglądów tych niezgodność, polegająca na tym, że z każdego z nich wynika zaprzeczenie drugiego. Bardzo łatwo tu o przesunięcie znaczeniowe i o zastąpienie pierwszego przekonania drugim. (...) Niezgodności dopatrywać się można w zdaniach języków, które różnią się tylko słownictwem, lecz nie znaczeniem słów. (Jedynak, 2007: 88)

Po przeprowadzeniu rachunków logicznych stwierdza, iż mocniejsza wersja tezy relatywizmu językowego jest fałszywa (Jedynak, 2007: 92), niemniej jednak teza pośrednia, mówiąca o istnieniu „równie dobrych” języków, może być przyjmowana po przyjęciu trzech dodatkowych założeń (Jedynak, 2007: 93): iż języki te równie dobrze służą komunikacji, równie dobrze kierują myśleniem, percepcją i orientacją w świecie oraz wykazują podobny stopień złożoności i wyrafinowania, a więc nie są przeciwstawieniem narzędzi „prymitywnych” i „precyzyjnych”. Ponadto Anna Jedynak zakłada, że odmienność języków jest związana nie z przekonaniami, lecz z odmiennymi, niezgodnymi postawami ludzi, opartymi na innych hierarchiach wartości poszczególnych społeczności, które odnoszą się do różnych 
spraw, dziedzin, zjawisk i procesów. Mając to na uwadze, proponuje modyfikację mocnej wersji tezy Sapira-Whorfa i sformułowanie jako słabszej i dotyczącej postaw, a nie światopoglądu. Brzmiałaby wówczas następująco:

Ukształtowanie języka jest związane z pewną hierarchią ważności spraw, z pewną postawą poznawczą wobec rzeczywistości, a postawy tego rodzaju bywają niezgodne w tym sensie, że wielce utrudnione jest łączne zajmowanie ich na serio. (Jedynak, 2007: 104)

Według Tomasza Nowaka kolejne argumenty przeciwko hipotezie Sapira-Whorfa wynikają z obserwacji (Nowak, 2011: 316), istnieją bowiem języki powinowate i pokrewne. Pierwsze to takie, których użytkownicy żyją we wspólnej kulturze, na przykład języki baskijski i hiszpański. Użytkownicy języków pokrewnych żyją zaś w różnych kulturach, na przykład języki Indian Nawaho i Apaczów. Hipoteza Sapira-Whorfa przywiązuje za dużą wagę do różnic, podczas gdy istnieją też uniwersalne aspekty języka, właściwości wspólne wszystkim językom badane w ramach szkoły gramatyki generatywnej Noama Chomsky’ego, która broni tezy o wrodzonej człowiekowi uniwersalnej gramatyce (Schaff, 1982: 6). Ponadto generatywizm akcentuje niezależność rozwoju językowego i poznawczego (Nowak, 2011: 316). Pierwszy dotyczy mowy, języka etnicznego, drugi zaś umysłu, języka myśli, który obejmuje symbole dla pojęć i ich kombinacje. W niektórych dziedzinach przeważa język myśli, który odróżnia konkret i abstrakcję, w innych zaś język etniczny, który jednoznacznie identyfikuje obiekty. Za Piotrem P. Chruszczewskim można w tym miejscu przywołać opracowaną przez Stephena Levinsona zmodyfikowaną hipotezę „neo-whorfiańską”, która stanowi próbę połączenia twierdzeń relatywizmu i uniwersalizmu (Chruszczewski, 2011: 72). Obejmuje ona trzy zdania: (1) „Możliwe jest, że wszystkie języki używają tych samych podstawowych konceptów semantycznych, ale różnią się w sposobie proponowania tych konceptów w celu uzyskania złożonych konceptów leksykalnych czy gramatycznych”; (2) „Uniwersalne koncepty są złożone w kulturowo-molekularne kombinacje, odpowiadające znaczeniom słów, co może odgrywać pewną rolę w myśleniu”; (3) „Użytkowników różnych języków łączy głębsza jedność psychiczna, ale posiadają oni cały repertuar różnych konceptów wykorzystywanych w swoich procesach myślenia" (Chruszczewski, 2011: 72). Udowodnienie tak zmodyfikowanej hipotezy wymaga odrębnych badań. Możliwe jest zatem poszukiwanie innych stanowisk pośrednich między relatywizmem a uniwersalizmem językowym (Gut, 2009: 43-47; Wierzbicka, 2007: 56-68).

Nowak podaje też argumenty z psychologii rozwojowej i poznawczej (Nowak, 2011: 316-317). Według hipotezy niejednakowych kosztów poznawczych przetwarzanie pewnych informacji jest łatwiejsze w jednym języku, a trudniejsze w innym, w związku z czym im bardziej złożona konstrukcja, tym później jest przyswajana. Przykładowo, choć dzieci polskie uczą się negacji wolniej niż angielskie, to sens negacji rozumieją tak samo. W tym ujęciu to rozwój poznawczy określa rozwój 
językowy. Ponadto zauważa się pewną regularność co do nazw barw w poszczególnych językach. Choć ich liczba jest różna, to jeśli dany język zawiera dwie nazwy, na przykład biały i czarny, a inny zawiera trzy nazwy, na przykład biały i czarny, to obejmuje też niebieski, zielony lub żółty. Przykład stanowi tu plemię Dani z Nowej Gwinei, które ma w swoim języku dwie nazwy barw: białą i czarną, ale jego członkowie rozpoznają jednak wszystkie barwy, ponieważ potrafią dobierać kolorowe krążki do wzorców barw (Nowak, 2011: 317). Jak podaje Antonina Kłoskowska, argumenty za hipotezą Sapira-Whorfa dotyczące percepcji kolorów zostały odrzucone przez późniejsze prace badawcze B. Berlina, P. Kaya i H. Conklina (Kłoskowska, 2007: 303). Udowodnili oni, iż wszystkie poznane systemy klasyfikacji podstawowych kolorów opierają się na uniwersalnym, jednolitym w obrębie gatunku ludzkiego mechanizmie percepcji barw.

Ostatnie argumenty wyróżnione przez Nowaka dotyczą gramatyki (Nowak, 2011: 317). Przykład stanowi tu porównanie języka angielskiego i chińskiego. Pierwszy wyraża tryb warunkowy w sposób gramatyczny, drugi w sposób leksykalny. Zaproponowano test zawierający pytania typu: „Gdyby zaszło X, to też Y. Zdarzenie X nie zaszło. Czy zaszło Y?". Pytania zostały sformułowane w trybie warunkowym - raz gramatycznie, raz leksykalnie. Za pierwszym razem Anglicy osiągali lepsze wyniki niż Chińczycy, za drugim Chińczycy zbliżone do Anglików.

\section{Podsumowanie}

Opracowanie miało na celu omówienie argumentów pozwalających na uznawanie poglądów Sapira i Whorfa za zasadne do wykorzystywania w dalszych opracowaniach teoretycznych i badaniach empirycznych oraz ich kontrargumentów. Słuszność „hipotezy Sapira-Whorfa” dotyczy głównie przyjmowania bądź słabszej wersji tej koncepcji, bądź traktowania jej jako poglądu o relatywizmie kulturowym, a nie relatywizmie językowym. W przypadku mocniejszej, skrajnej postaci koncepcja ta wymaga dalszych badań pozwalających na jej weryfikację.

Jednocześnie zasadne jest podejmowanie prac badawczych, które pozwoliłyby na zweryfikowanie mniej i bardziej jawnego podzielania poglądów Sapira i Whorfa we współczesnych pracach naukowych dotyczących badań nad społecznościami komunikującymi się głównie za pośrednictwem technologii informatycznych i telekomunikacyjnych, jak internetowe fora dyskusyjne, gry sieciowe i serwisy społecznościowe nurtu Web 2.0. Wartościowe mogą być analizy dotyczące uczestnictwa w tych grupach i ich oddziaływania na zainteresowania, działalność i kontakty społeczne ich członków. Hipoteza może być także przydatna do analiz zróżnicowania i rozwoju języków wykorzystywanych w zbiorowościach sieciowych oraz wspólnotach hobbystycznych i fanowskich - „nowych plemionach” 
(koncepcja Michaela Maffesoli’ego). Wreszcie zasadne jest prowadzenie badań opartych na hipotezie, które mogłyby wzbogacić, jak również służyć do krytyki, koncepcję konwergencji mediów autorstwa Henry’ego Jenkinsa (Jenkins, 2007), czyli procesu upodobniania się zasad ich funkcjonowania, ich łączenia, korporacyjnego lub oddolnego przepływu treści między platformami medialnymi oraz migracji publiczności za pożądanymi typami przekazów.

\section{Literatura}

Barnard A., Spencer J. (2008). Sapira-Whorfa hipoteza. [W:] Encyklopedia antropologii społeczno-kulturowej. Red. A. Barnard, J. Spencer, s. 545-546. Warszawa

Burszta W.J. (1998). Antropologia kultury. Tematy, teorie, interpretacje. Poznań

Chruszczewski P.P. (2011). Językoznawstwo antropologiczne. Wrocław

Golka M. (2008). Socjologia kultury. Warszawa

Gut A. (2009). O relacji między myśla a językiem. Lublin

Herzfeld M. (2004). Antropologia. Praktykowanie teorii w kulturze i społeczeństwie. Kraków Jedynak A. (2007). Doświadczenie i język. Warszawa

Jenkins H. (2007). Kultura konwergencji. Zderzenie starych i nowych mediów. Warszawa

Kłoskowska A. (2007). Socjologia kultury. Warszawa

Maffesoli M. (2008). Czas plemion. Schyłek indywidualizmu w społeczeństwach ponowoczesnych. Warszawa

Marody M. (1987). Technologie intelektu. Językowe determinanty wiedzy potocznej i ludzkiego działania.Warszawa

McQuail D. (2007). Teoria komunikowania masowego. Warszawa

Nowak T. (2011). Język w świetle odkryć nauki. Kraków

Pisarek W. (2008). Wstęp do nauki o komunikowaniu. Podręcznik akademicki. Warszawa

Sapir E. (1978). Kultura, język, osobowość. Wybrane eseje. Warszawa

Schaff A. (1964). Język a poznanie. Warszawa

Schaff A. (1982). Wstęp do polskiego wydania. [W:] B.L. Whorf, Język, myśl i rzeczywistość, s. 5-31. Warszawa

Słaboń A. (2001). Hipoteza Sapira-Whorfa. [W:] M. Pacholski, A. Słaboń. Słownik pojęć socjologicznych, s. 58. Kraków

Słownik socjologii i nauk społecznych (2005). Red. M. Gordon. Warszawa

Stępień A.B. (1995). Wstęp do filozofii. Lublin

Whorf B.L. (1982). Język, myśl i rzeczywistość. Warszawa

Wierzbicka A. (2007). Słowa klucze. Warszawa

Wittgenstein L. (1997) Tractatus logico-philosophicus. Warszawa

Woleński J. (2005), Epistemologia. Poznanie, prawda, wiedza, realizm. Warszawa

Wstęp do kulturoznawstwa. (2007). E. Baldwin, B. Longhurst, S. McCracken, M. Ogborn, G. Smith (aut.). Poznań

Ziółkowski M. (1998). Język i komunikowanie. [W:] Encyklopedia socjologii. T. 1, s. 370-375. Red. W. Kwaśniewicz. Warszawa 


\section{The Sapir-Whorf Hypothesis - a Review of Argumentation of Followers and Adversaries}

\section{Summary}

The paper is aimed at presenting a critical review of the literature on views of E. Sapir and B.L. Whorf, which are collectively called as "Sapir-Whorf hypothesis". Views of these authors on the relationship between language and cognition caused scientific dispute, which remains relevant in the context of contemporary growing importance of interdisciplinary research as well as research in cultural diversity, multiculturalism and intercultural cooperation. This debate has to be placed in the context of global changes related to dissemination of digital information and communication technologies. E. Sapir and B.L. Whorf concept is inspiring for study of contemporary divided and fragmented public discourse. Contemporary public discourse is conducted not only through the mass media, but also in different, often closed, groups by such spaces like online groups and discussion forums, social networking sites compatible with Web 2.0 current, online games. Article shows assumptions of Sapir-Whorf hypothesis, bring closer a discussion on the arguments of its proponents and opponents as well as identifies future directions of research.

The main assumption of E. Sapir and B.L. Whorf concept was created in the late 20th and 30 s of 20th century. This is an assertion that human thinking is determined by language. Structure of language determine perception, classifying, ways to recognize the reality by man, affect his state of mind and qualities of thinking about reality. Consequently language itself includes, somewhat, image of the world. Sapir-Whorf hypothesis is derived from American ethnolinguistics anthropological school studies of F. Boas. However, it is not consistent with views of this researcher because he rejected theories granting creative role of language in relation to culture, acknowledging opposite direction of that relationship.

Sapir-Whorf hypothesis according to T. Nowak, A. Barnard, J. Spencer and A. Schaff is located in the mainstream of linguistic relativism, and takes weaker form (E. Sapir views) and stronger (B.L. Whorf views), which are situated between the descriptive and epistemological relativism. In the first case, need for acceptance of different cultures, and thus different ways of perception, categorization and interpretation of the world is postulated. While second presumes no unity of human psyche and criticism of general cultural theories. As evidenced by A. Jedynak in weaker version languages of the ethnic communities often differ quite significantly by sounds of words and their meanings, thus their speakers communities have different worldviews. In stronger version (B.L. Whorf) worldviews are not only different, but they cannot be reconciled - adoption of one excludes others. Hence ability to communicate and interlingual translation and interpretation of the meanings functioning in other cultures are questionable. At the same time, there is no superiority of one language over the other, because they all have their advantages and disadvantages.

Many arguments in favor of Sapir-Whorf hypothesis as a basis for construction of further assertions is pointed out in professional literature. It is assumed that a weaker version of hypothesis is undeniable - there is a link between language and thinking. However, a strong version, in which language is the only cause of thinking is rejected. Defenders of hypothesis recognize that it has permanent ability to generate ideas and discussion on basic nature for philosophy and anthropology. Its rejection would cancel out legitimacy of research on diversity and development of the human species. Adoption of Sapir-Whorf hypothesis is therefore justified when 
it is assumed that proclaims cultural, not language relativism. Thus it directs study of values, norms and social systems from the cultural perspective of a given society, not from the point of researcher view. The hypothesis is supported either by experimental studies (different frames of reference for the location of objects taken by people from different cultures) as well as by study of grammar (cultural differences in naming and categorizing objects and actions).

Proponents of hypothesis are mainly anthropologists and ethnolinguistics. Recognizing lack of sufficient empirical basis for the verification and falsification of Sapir-Whorf views they consider them as requiring further research for example, on the non-linguistic testimonies of mental processes and ways of describing qualities in different languages, which are responsible for different ways of thinking, except for researchers own speech. A weaker version of the Sapir-Whorf hypothesis either stimulates the joint work of different cultures representatives and converging in many ways interpretation of events and broadening cognitive perspective. It can also ease active involvement of anthropologists in to problems of people and natural environment relations, as well as help in understanding differences in environmental protection. The hypothesis also allows explaining the differences between cultures in the description and explanation of relevant to them issues, such as multiplicity of rice names or snow colors as well as used to study manifestations of totalitarian power "newspeak".

Number of arguments is also provided by Sapir-Whorf hypothesis opponents. A. Schaff introduces such as following: ambiguous and ill-defined starting categories of hypothesis; vague wording; metaphysical claims (understanding as a 'kaleidoscopic stream of impressions', language contains a view of the world); absurd claim of untranslatability of different languages. Moreover A. Schaff rejects an extreme version of linguistic relativism for four reasons: (1) even colloquial observation shows that the languages are mutually translatable, although the translation may require in-depth knowledge of the culture of a given society; (2) if a different language systems generate different images of the world, people that use them would behave differently under the same conditions; (3) there are cultural universals, linguistic universals - All languages have some common characteristics which enable their translation and communication connected with common biological fate of humanity; (4) languages are constantly changing, so boundaries of their conceptual apparatus is blurring, but phonetics, grammar and imageemotional coloration remains unchanged.

Opponents also suggest that the American school of anthropology on the ground, which the Sapir-Whorf hypothesis was created, is only one perspective of research on culture and language. Competitive concepts are also in the analysis of communication processes, classification of signs and anthropological linguistics paradigms. Hypothesis does not have a sufficient methodological basis. It rather refers to related views of those authors instead of their joint work. Hypothesis does not show a clear direction of causal relationship - it is unknown whether language impact implies one way on thinking, or impact have some feedback features. Hypothesis is applicable only to ethnic languages, while cannot be applied to artificial, formal languages, characterized by a coherent structure, based on an agreement that allows expression of scientific claims.

Against the Sapir-Whorf hypothesis logic, observation and experimental are raised. On the basis of logic only a weaker version of the hypothesis may be accepted, which assumes that there are differences between languages and worldviews. Observations shows that there are daughter (shared culture) and related (different culture) languages. While the Sapir-Whorf hypothesis attaches importance only to the differences. Experimental arguments are derived from unequal cognitive costs hypothesis - processing certain information is easier in one language, and difficult in another, thus the more complex language structure, the later is educated. 
In conclusion, it is considered that it is reasonable to adopt only a weaker version of the Sapir-Whorf hypothesis, or to treat it as a notion of cultural, not language, relativism. Stronger version of concept requires further study to verification. Modern research may relate to checking approximately explicitly sharing of E. Sapir and B.L. Whorf ideas in analyzes of communities that communicate mainly through new information and communication technologies. Hypothesis can also be useful for analysis of differentiation and development of languages used in network collectivities and hobbyist, fans communities - "new tribes" (M. Maffesoli concept). Sapir-Whorf hypothesis also allows enrichment and critique of media convergence concept (H. Jenkins), that is, the process of assimilation rules of their functioning, corporate or bottom-up controlled flow of content across multiple media platforms and migration of audience for desired types of content. 
